\title{
Measurements of Periodic Signals Phase Shifts with Application of Direct Digital Synthesis
}

\author{
I.V. Gula, O.I. Polikarovskykh, K.L. Horiashchenko, L.V. Karpova, V.M. Melnychuk
}

Khmelnitsky National University,

Instytutska str., 11, Khmelnitsky 29016, Ukraine

Received 16.04.2019

Accepted for publication 05.06.2019

\begin{abstract}
The development of new methods and high-bit instruments for measuring phase shifts of high-frequency periodic signals with high speed for radar and radionavigation tasks is an actual task. The purpose of this work is to create a new phase shift meter for high-frequency periodic signals based on the double-matching method using direct digital frequency synthesis.

On the basis of the proposed mathematical model of phase shift measurements of periodic signals by the method of double coincidence using the statistical accumulation of pulse coincidences, a functional diagram of a digital phase shift meter of periodic signals using a direct digital frequency synthesizer is developed. This allowed the implementation of an 8-bit converter phase shift signal to the code on the programmed logic integrated circuit EPM240T100C5N firm Altera.

The digital phase shift meter of periodic signals based on the double-matching method consists of two comparators, two short-wave pulse generators, a direct digital frequency synthesizer, two pulse counter control circuits, two short pulse coincidence circuits, two pulse counting circuits, four clock counters, four registers, a microcontroller and an indicator. Block diagram of a double-matching digital phase meter using direct digital sintesizer use minimal hardware logic.

In the developed phase shift meter, due to the use of the double-matching method, the time delay between signals does not depend on the period of input signals and can be found when changing the frequency of periodic pulses in wide limits. Measurement errors will be determined mainly by the duration of the pulses of coincidence. The use of statistical accumulation of pulse coincidence in the basis of the work allowed eliminating the restrictions on the duration of pulses of known non-ionic meters.

On the basis of the obtained results, a high-bit converter of phase shifts of high-frequency periodic signals into a binary code with high speed for problems of industrial tomography, radar and radionavigation can be developed.
\end{abstract}

Keywords: the double coincidence method, nonius, measurement, phase shift meter, direct digital frequency synthesizer.

DOI: $10.21122 / 2220-9506-2019-10-2-169-177$

\begin{tabular}{ll}
\hline Адрес для переписки: & Address for correspondence: \\
И.В. Гула & I.V. Gula \\
Хмельницкий национальный университет, & Khmelnitsky National University, \\
ул. Институтская, 11, г. Хмельницкий 29016, Украина & Instututska str., 11, Khmelnitsky 29016, Ukraine \\
e-таil: holmепеtwork@gmail.com & e-mail: holmenetwork@gmail.com \\
\hline Для цитирования: & For citation: \\
I.V. Gula, O.I. Polikarovskykh, K.L. Horiashchenko, L.V. Karpova, & I.V. Gula, O.I. Polikarovskykh, K.L. Horiashchenko, L.V. Karpova, \\
V.M. Melnychuk. & V.M. Melnychuk. \\
Measurement of Periodic Signals Phase Shifts with Application & Measurement of Periodic Signals Phase Shifts with Application \\
of Direct Digital Synthesis. & of Direct Digital Synthesis. \\
Приборы и методы измерений. & Devices and Methods of Measurements. \\
2019. - Т. 10, № 2.- С. 169-177. & 2019, vol. 10, no. 2, pp. 169-177. \\
DОI: 10.21122/2220-9506-2019-10-2-169-177 & DOI: 10.21122/2220-9506-2019-10-2-169-177
\end{tabular}




\title{
Измерения фазовых сдвигов периодических сигналов с применением прямого цифрового синтеза
}

\author{
И.В. Гула, О.И. Поликаровских, К.Л. Горященко, Л.В. Карпова, В.М. Мельничук
}

Хмельницкий национальный университет,

ул. Институтская, 11, г. Хмельницкий 29016, Украина

Поступила 16.04.2019

Принята к печати 05.06.2019

Разработка новых методов и высокоразрядных средств измерения фазовых сдвигов высокочастотных периодических сигналов с высоким быстродействием для решения задач радиолокации, радионавигации является актуальной задачей. Целью данной работы являлось создание нового измерителя фазовых сдвигов высокочастотных периодических сигналов на основе метода двойного совпадения с использованием прямого цифрового синтеза частот.

На основе предложенной математической модели измерения фазовых сдвигов периодических сигналов методом двойного совпадения с использованием статистического накопления импульсов разработана функциональная схема цифрового измерителя фазовых сдвигов периодических сигналов с использованием прямого цифрового синтезатора частот. Это позволило реализовать 8-разрядный преобразователь фазового сдвига сигналов в код на программируемой логической интегральной схеме EPM240T100C5N фирмы Altera.

Цифровой измеритель фазовых сдвигов периодических сигналов на основе метода двойного совпадения состоит из: двух входных устройств, двух формирователей коротких импульсов, прямого цифрового синтезатора частоты, двух схем управления счетчиками импульсов, двух схем совпадений коротких импульсов, двух схем управления счетчиками импульсов, четырех счетчиков тактовых импульсов, четырех регистров, микроконтроллера и индикатора. Предложенная блок схема реализации измерителя имеет минимальную аппаратную сложность.

За счет использования метода двойного совпадения временная задержка между сигналами не зависит от периода входных сигналов и может быть найдена при изменении частоты периодических импульсов в широких пределах. Погрешности измерения будут определяться в основном только длительностью импульсов совпадений. Использование в основе работы статистического накопления импульсов позволило устранить ограничения на длительность импульсов известных нониусных измерителей.

На основе полученных результатов исследования разработан высокоразрядный преобразователь фазовых сдвигов высокочастотных периодических сигналов в двоичный код с высоким быстродействием для задач радиолокации и радионавигации.

Ключевые слова: метод двойного совпадения, нониус, измерение, измеритель сдвига фазы, прямой цифровой синтезатор частоты.

DOI: $10.21122 / 2220-9506-2019-10-2-169-177$

\begin{tabular}{ll}
\hline Адрес для переписки: & Address for correspondence: \\
И.В. Гула & I.V. Gula \\
Хмельницкий национальный университет, & Khmelnitsky National University, \\
ул. Институтская, 11, г. Хмельницкий 29016, Украина & Instututska str., 11, Khmelnitsky 29016, Ukraine \\
e-таil: holmenetwork@gmail.com & e-mail: holmenetwork@gmail.com \\
\hline Для цитирования: & For citation: \\
I.V. Gula, O.I. Polikarovskykh, K.L. Horiashchenko, L.V. Karpova, & I.V. Gula, O.I. Polikarovskykh, K.L. Horiashchenko, L.V. Karpova, \\
V.M. Melnychuk. & V.M. Melnychuk. \\
Measurement of Periodic Signals Phase Shifts with Application & Measurement of Periodic Signals Phase Shifts with Application \\
of Direct Digital Synthesis. & of Direct Digital Synthesis. \\
Приборы и методы измерений. & Devices and Methods of Measurements. \\
2019. - Т. 10, № 2.- С. 169-177. & 2019, vol. 10, no. 2, pp. 169-177. \\
DОI: 10.21122/2220-9506-2019-10-2-169-177 & DOI: 10.21122/2220-9506-2019-10-2-169-177 \\
\hline
\end{tabular}




\section{Introduction}

In modern measuring devices, different methods of phase determination are used, such as: electroncounting method for determining the phase shift of signals without frequency conversion (at frequency up to $1 \mathrm{MHz}$ ), with frequency conversion (at frequencies above $1 \mathrm{MHz}$ ), non-linear measurement methods (single and multiple). The electroniccounting method has a number of shortcomings: with increased accuracy, the requirements for the speed of the elements of the circuit (in particular, pulse counters) are sharply increasing, and the measuring time is also increasing. The use of non-native methods of measurement allows partial elimination of this measurement problem.

Non-native methods can improve the accuracy of measuring phase shifts of signals using the same element base. In addition, the nonius method allows for high accuracy of measurement when using reference frequencies close to the incoming signal frequencies. Application of the principle of nondimensional measurements can significantly reduce the duration of one measurement cycle.

In recent years widespread use has been made of nonius methods of measurement. They are used in the construction of the time-to-digital converter [1], distance meters [2], radio frequency identification sensors, as well as phase shift meters [3]. The use of nonius methods of measurement allows to partially eliminate the shortcomings of the electron-counting method of measuring phase shifts of signals. Nonius methods allow increasing the accuracy of measurement of phase shifts of periodic signals using the same elemental base. In addition, the nonius method allows for high accuracy of measurement when using reference frequencies close to the input signal frequencies [4].

Nonius methods have certain limitations associated with the need to change the duration of pulses when the frequency of input signals changes, to provide the required measurement accuracy. That is, with the increase in the frequency of input signals, it is necessary to reduce the duration of the pulses of the reference frequency, which makes it difficult to use these methods at high frequencies. In this case, it is necessary to form impulses of nanoseconds and picoseconds duration. Ensuring the stability of the duration of these impulses is difficult enough to implement hardware [5].

The measured signal is usually sufficiently long. During this time there can be hundreds and thousands of its periods. At the same time, the parameters of this signal remain stable during the measurement. Noniuse method uses the first two coincidences that occupy a small part of the time interval, which decreases with increasing frequency. Further increase in frequency leads to the need to use shorter pulses, hardware to create difficult to ensure repeatability of their characteristics. The time increment of the measurement scale of the non-native method should decrease in proportion to the reduction of the measured signal period. And the number of samples for this scale is limited by the speed of the noniuse meter. The aim of the work is to develop a method for measuring phase shift and its practical implementation, using more than two coincidences.

To eliminate the restrictions on the duration of impulses of known nonunique methods, a method of measurement is proposed based on a double match with the statistical accumulation of the number of pulses per cycle of measurement.

\section{Main part}

Let's consider a single nonius method, which consists of measuring the number of non-null pulses from the moment the input signal is received and to the first coincidence of the main and nonnegative signals [6]. The accuracy of the method depends on the duration of the nonius signal pulses. The main node of the nonius phase meter is the impulse generator of the nonius sequence. The task of which consists in forming a sequence of impulses, duration $\tau$ and period $T$ the following of which must be in a certain way connected with the period of following of the impulses of the test signal:

$\tau=\frac{1}{36 \cdot 10^{k}} T_{x}$,

and a reiteration period:

$T=\left(1-\frac{1}{36 \cdot 10^{k}}\right) T_{x}$,

where $k$-the coefficient is selected based on the specified measurement accuracy: with accuracy $1^{\circ}$ $k=1$; with accuracy $0,1^{\circ} k=2$; with accuracy $0,01^{\circ}$ $k=3 ; T, T_{x}$-periods of the reference and input signals.

To obtain a phase shift counting directly in radians, the shaper must produce a series of pulses of duration: 


$$
\tau=\frac{1}{2 \pi \cdot 10^{k}} T_{x},
$$

with a reiteration period:

$$
T=\left(1-\frac{1}{2 \pi \cdot 10^{k}}\right) T_{x} \text {. }
$$

In nonius meters, the increase in accuracy by several orders of magnitude leads to an increase in measurement time. There are also high demands on the stability of the formation of the period of the reference and nonius sequences, due to the accumulation of errors in the measurement process due to the addition over time of the duration of separate periods.

The elimination of some of the deficiencies of the nonius method is carried out by applying the method of multiple nonius. The method involves the use of several nonius scales in the conversion process (one for each rated discharge or group of discharges) and is implemented in two ways. The first way is characterized by the fact that all the nonius scales are compared with another reference scale. The second way of implementing the method of multiple nonius is associated with the use of the preliminary transformation stage at each subsequent stage as a reference nonius scale.

When measuring phase shifts of signals by the multiple-nonius method, the memory device reproduces a time interval proportional to the phase shift angle. For example, taking into account expressions (1) and (2) for 3 digits, the system of equations will be:

$$
\begin{aligned}
& T_{1}=\frac{26}{36} T_{x} ; T_{2}=\frac{35}{36} T_{x} ; T_{3}=\frac{35,9}{36} T_{x} \\
& \tau_{1}=\frac{10}{36} T_{x} ; \tau_{2}=\frac{1}{36} T_{x} ; \tau_{3}=\frac{1}{360} T_{x}
\end{aligned}
$$

where $T_{x}$ - period of input signal; $T_{1}, T_{2}, T_{3}$ - periods of reference signals; $\tau_{1}, \tau_{2}, \tau_{3}$ - pulse durations.

In this case, the readings counter of senior level will be calculated in hundreds of degrees, the second level in tens of degrees; third level - units of degrees, etc.

From (3) it can be seen that the hardware complexity of this method increases significantly, the number of generators and pulse shapers increases. For each discharge need one nonius sequence generator and pulse generator.

In the method of multiple nonius, the performance of the meter is improved, its dynamic characteristics are improved compared with the single nonius method.
Resolution in nonius methods is defined by the following expression:

$\delta_{\varphi}=\frac{360 \cdot \Delta \tau}{T_{x}}=360 \cdot \Delta \tau \cdot f_{x}$,

where $\Delta \tau=\left|T_{x}-T_{0}\right|-$ the ratio between the periods of the input and reference signals; $f_{x}$ - input signals frequency.

Expression (4) indicates a problem with highfrequency phase angle meters. With an increase in input frequency, the decrease $\Delta \tau$ with a constant value $\delta_{\varphi}$ is inevitable. But decrease $\Delta \tau$ requires the use of highspeed and highly stable digital components. That is, the decrease $\Delta \tau$ leads to a decrease in the duration of the coincidence pulses. So, in the scheme of coincidence all shorter coincidence impulses should be formed.

The duration of the coincidence pulses in the nonius methods is determined from the expression: $\tau=\left|T_{x}-T_{0}\right|$.

Expression (5) determines that the pulse duration must be equal to the difference between the periods of the input and reference signals. According to the increasing frequency of the input signals, the duration of the coincidence pulses should be reduced.

Table 1 shows the values of the pulse duration $\tau$, which is necessary to provide the necessary resolution at different frequencies, according to expressions (1), (2).

Table 1

\section{Pulse duration using the nonius methods}

\begin{tabular}{lllll}
\hline Frequency & \multicolumn{3}{c}{$\begin{array}{c}\text { Duration of coincidence pulses (seconds) } \\
\text { with a minimum error, measuring } \\
\text { the angle of the phase shift (degrees) }\end{array}$} \\
\cline { 2 - 5 } & To $1^{\circ}$ & To 0, $1^{\circ}$ & To 0,01 & To \\
& & & & $0,001^{\circ}$ \\
\hline $1 \mathrm{kHz}$ & $3 \times 10^{-6}$ & $3 \times 10^{-7}$ & $3 \times 10^{-8}$ & $3 \times 10^{-9}$ \\
$10 \mathrm{kHz}$ & $3 \times 10^{-7}$ & $3 \times 10^{-8}$ & $3 \times 10^{-9}$ & $3 \times 10^{-10}$ \\
$100 \mathrm{kHz}$ & $3 \times 10^{-8}$ & $3 \times 10^{-9}$ & $3 \times 10^{-10}$ & $3 \times 10^{-11}$ \\
$500 \mathrm{kHz}$ & $3 \times 10^{-9}$ & $3 \times 10^{-10}$ & $3 \times 10^{-11}$ & $3 \times 10^{-12}$ \\
$1 \mathrm{MHz}$ & $3 \times 10^{-9}$ & $3 \times 10^{-10}$ & $3 \times 10^{-11}$ & $3 \times 10^{-12}$ \\
$10 \mathrm{MHz}$ & $3 \times 10^{-10}$ & $3 \times 10^{-11}$ & $3 \times 10^{-12}$ & $3 \times 10^{-13}$ \\
\hline
\end{tabular}

Table 1 shows that in nonius methods, the principled problem is that with the increase in the frequency of input signals, we need to generate pulses of shorter duration to provide the required resolution. That is, with the increase in the frequency of input signals, it is necessary to reduce the duration of the pulses of the reference frequency, which makes it difficult to use these methods at high frequencies. 


\section{Solution}

In order to eliminate the disadvantages of nonius methods [4-8] due to the necessity of using the minimum duration pulses, it was suggested to use the method of double coincidence with the statistical accumulation of pulses, which made it possible to increase the accuracy of determining the phase shift angle in the larger frequency range by achieving a smaller equivalent pulse duration with an acceptable measurement time.

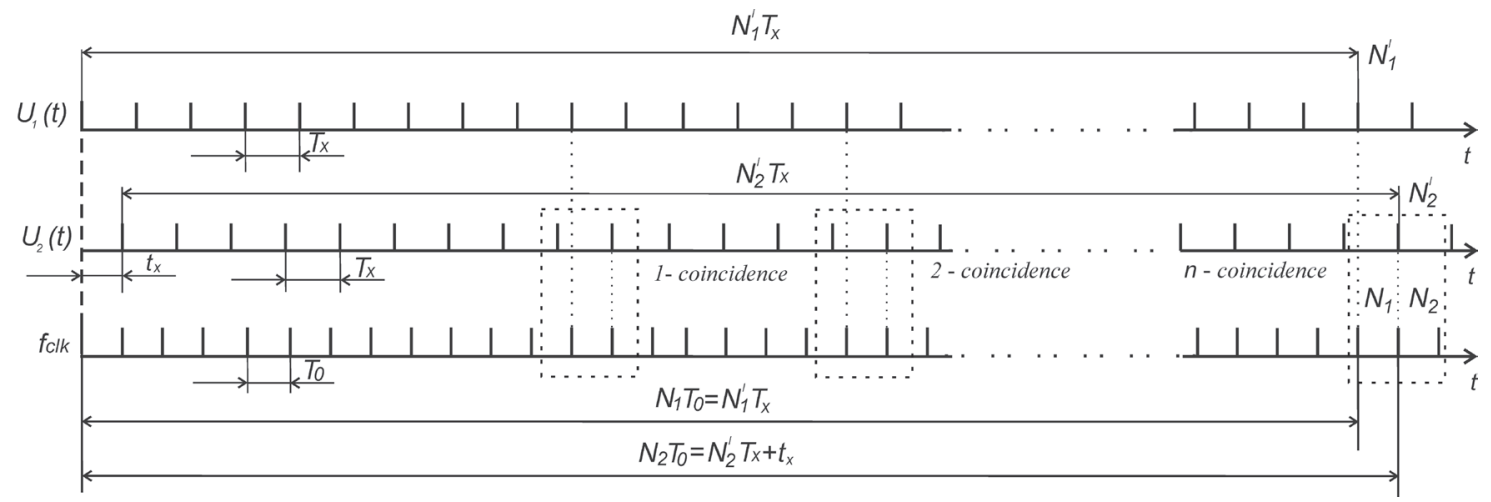

Figure 1 - Time charts of the double-matching method with the statistical accumulation of pulses

The method of double coincidence can be measured phase shift $\varphi_{x}$ (Figure 1), that is, an equivalent interval $t_{x}$, to which the two periodic pulse sequences with a period are shifted $T_{x}$.

Expression for measuring the time interval $t_{x}$ double-matching method:

$t_{x}=\left(\frac{N_{1}^{\prime} N_{2}-N_{2}^{\prime} N_{1}}{N_{1}^{\prime}}\right) \cdot T_{0}$,

where $N_{1}$ - the first periodic sequence of pulses with a period $T_{0} ; N_{2}$ - second periodic sequence of pulses with a period $T_{0} ; N_{1}{ }^{\prime}$ - the first periodic sequence of pulses with a period $T_{x} ; N_{2}^{\prime}-$ second periodic sequence of pulses with a period $T_{x}$.

Analysis (6) shows that tx does not depend on $T_{x}$. So, the time interval can be found when changing the frequency of periodic pulses in wide limits. Measurement errors will be determined mainly by the duration of the pulses $\tau$.

In the general case, the phase shift $\varphi$ of the signals is determined:

$\varphi_{x}=\frac{\tau}{T} \cdot 360^{\circ}$.

In expression (7), unknown is only $\tau$ is the time interval between the moments when the signals are in identical phases. In order to measure the phase by the proposed method, it is only necessary to determine $\tau$, in our case it is identical $t_{x}$ - the interval on which the shifted two periodic pulse sequences are shifted. That is, $\tau=t_{x}$.
The expression for measuring the phase shift of the signal by the proposed method will have the form:

$\varphi_{x}=\left(\frac{N_{1}^{\prime} N_{2}-N_{2}^{\prime} N_{1}}{N_{1}}\right) \cdot 360^{\circ}$.

The main advantages of the double-matching method are to increase the accuracy of the measurement in comparison with the nonius methods due to the almost complete elimination of the sampling error (methodical error).

Additional sources of errors arise due to incomplete coincidence (partial overlapping) of pulses in the coincidence scheme, duration and form of countable impulses.

The use of statistical accumulation of pulses allows us to use impulses of longer duration than in nonius methods of measurement, under fulfilling the condition:

$$
\tau_{\text {coincidence }} \geq \tau \text {, }
$$

where $\tau_{\text {coincidence }}$-duration of pulses in the method of double coincidence with the statistical accumulation of pulses; $\tau$-duration of impulses in nonius methods.

The pulse duration for the double-matching method with the statistical accumulation of the pulses will be determined by the expression:

$\frac{T_{x}}{2}>\tau_{\text {coincidence }} \geq \frac{T_{x}}{36 \cdot 10^{k}}$,

where $T_{x}$ - input signal period (Figure 1). 
The analysis of expressions (9), (10) shows that the method of double matching with the statistical accumulation of pulses provides the possibility of setting the pulse duration in a sufficiently wide range. That is, it allows you to use constant pulse duration over a wide range of input frequencies. And since there is a multiplicity of coincidences, the effective duration of the coincidence pulses begins to decrease in the number of times of coincidences:

$\tau_{e}=\frac{\tau_{\text {coincidence }}}{n}$,

where $n$ - number of matches.

When growing $n \rightarrow \infty, \tau_{\text {coincidence }} \rightarrow 0$, and taking into account expression (4), the potential error of measurement of the phase shift angle also tends to zero. From a practical point of view it is clear that achievement $n \rightarrow \infty$ it will take an infinitely long time, it is impractical.

The measurement time can be determined as:

$t=n \cdot t_{\text {coincidence }}$,

where $t_{\text {coincidence }}$ - time between matches.

Table 2 shows the pulse duration values using the double-matching method with the statistical accumulation of pulses, expressions (9), (10).

\section{Table 2}

\section{Duration of pulses using a double-matching method with the statistical accumulation of pulses}

\begin{tabular}{llll}
\hline $\begin{array}{l}\text { Fre- } \\
\text { quency }\end{array}$ & $\begin{array}{r}\text { Duration of pulses of coincidence (seconds) } \\
\text { with a minimum error of measurement of the } \\
\text { angle of the phase shift (degrees) }\end{array}$ \\
\cline { 2 - 4 } & \multicolumn{5}{c}{ To $1^{\circ}$ To $0,1^{\circ}$ To $0,01^{\circ}$ To } \\
& & $0,001^{\circ}$ \\
\hline $1 \mathrm{kHz}$ & $\geq 3 \times 10^{-9}$ & $\geq 3 \times 10^{-9}$ & $\geq 3 \times 10^{-9}$ \\
$10 \mathrm{kHz}$ & $\geq 3 \times 10^{-9}$ & $\geq 3 \times 10^{-9}$ & \\
$100 \mathrm{kHz}$ & $\geq 3 \times 10^{-9}$ & $\geq 3 \times 10^{-9}$ & \\
$500 \mathrm{kHz}$ & $\geq 3 \times 10^{-9}$ & & \\
$1 \mathrm{MHz}$ & $\geq 3 \times 10^{-9}$ & $\geq 3 \times 10^{-9}$ & \\
$10 \mathrm{MHz}$ & $\geq 3 \times 10^{-9}$ & & \\
\hline
\end{tabular}

Table 2 shows that pulses of greater duration (10) can be used in the double-matching method at the same frequencies and resolution, as in nonius methods, due to the statistical accumulation of pulses. The method of double matching with the statistical accumulation of pulses allows measuring phase shifts of signals in higher frequency bands.

On the basis of the mathematical model $(8,10)$, the structure of the double-matching digital phase meter with the use of direct digital synthesizer (DDS) has been developed, see Figure 2:

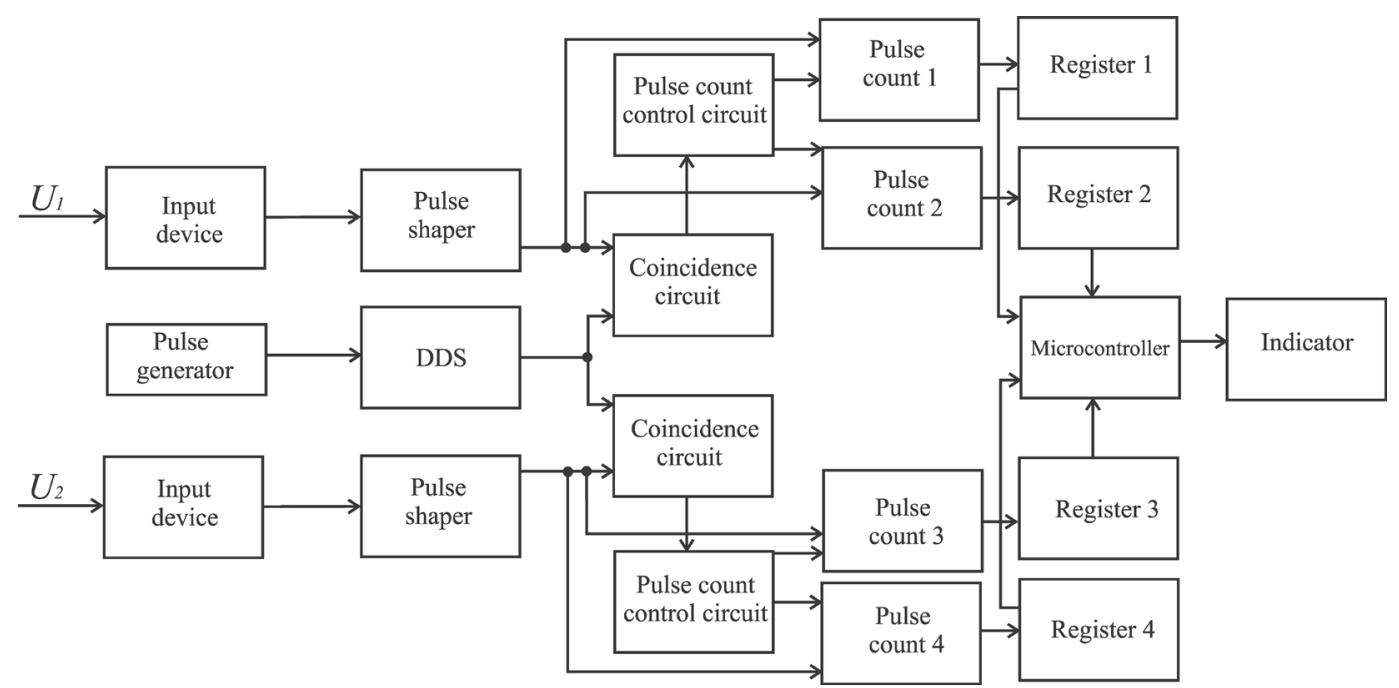

Figure 2 - Block diagram of a double-matching digital phase meter using direct digital synthesizer

The digital phase meter consists of the following blocks: two input devices that receive signals of the form $U_{1} \cos (\omega t)$ and $U_{2} \cos (\omega t+\varphi)$, the phase shift between which it is necessary to measure, two pulse shapers, two pulse count control circuits, two coincidence circuits, four counters pulses, four registers, pulse generator, DDS, microcontroller and indicator.
One input device used as source of reference input signal for measurer, and another used as source of signal to be measured. Each of pulse shapers are independent devices. Main purpose of shaper is generating pulses with stable and repeated in time parameters - width, rising and falling edges. Each shaper can be as integrated part of input device. 
Pulse generator as reference source for DDS with DDS gives us wide-range generator with fast and reliable software control. This DDS allows us to have stable source of reference pulses for coincidence procedure itself.

As we can see from Figure 2, double-matching digital phase meter use two similar but independent parts - upside part consist of Pulse counter 1 and Pulse counter 2, Register 1 and 2. And downside part consist of Pulse counter 3 and Pulse counter 4, Register 3 and 4. From the values of Register 1, Register 2, Register 3 and Register 4 with use (8), Microcontroller take decision about which input device is used as reference $U_{1} \cos (\omega t)$. Block diagram of a double-matching digital phase meter using DDS shown in Figure 2 use minimal hardware logic.

Timing diagrams of the operation of the phase meter are shown in Figure 3:

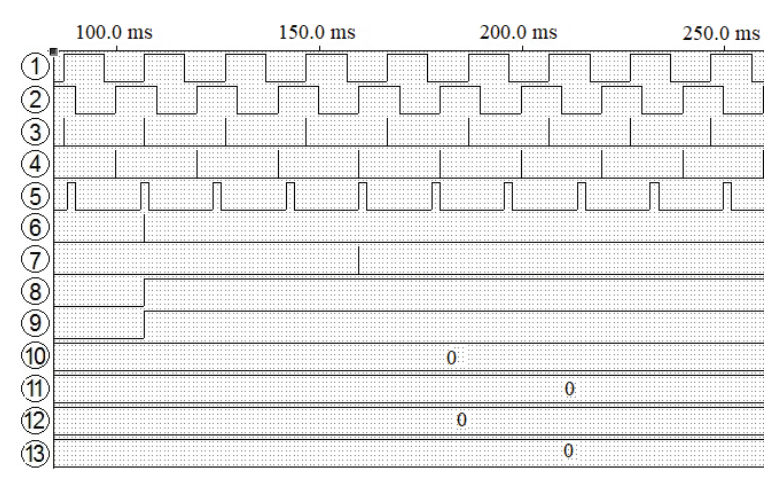

$a$

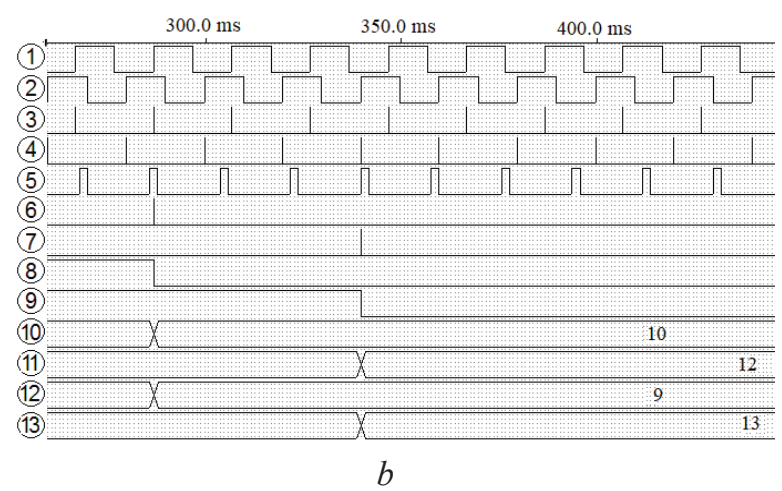

Figure 3-Timing diagrams of the operation of the phase meter: $a$-start of measurement; $b$-completion of the measurement

The method of measuring the phase (Figure 3), which is realized by the proposed structural scheme, is as follows. In input devices, analog input signals are converted to digital signals of a rectangular shape (diagrams 1,2) with preservation of the frequency and phase relations between them. Shaper pulses convert rectangular waveforms into short pulses (diagrams 3,4). The coded frequency synthesizer generates a reference signal (diagram 5). The synthesizer is based on a phase accumulator in a non-positional system of numbers $[9,10]$. The impulses of the two input sequences are compared to the signal that forms the DDS. At the output of the coincidence schemes, we get short coincidence impulses (diagrams 6,7). Further, the coincidence pulses enter the pulse count control circuitry, which form the control signals for the start and end of the count (Figure 8, 9). Four pulse counters count the values of the numbers $N_{1}, N_{1}{ }^{\prime}$, $N_{2}, N_{2}^{\prime}$. The calculated pulses are then written to the data registers (diagrams 10-13), the microcontroller reads the data from the registers, calculates the phase shift values according to (10), and outputs the value of the phase shift angle on the indicator. The process of calculating pulses of coincidence cyclically repeats itself.

The simulation of the proposed structure of the digital phase meter in the MAX + PLUS II BASELINE software $\mathrm{v} 10.0$ from the Altera company was carried out. On the basis of which the analytical expression of the absolute error is established:

$$
\Delta \varphi=\left[\frac{\left(T_{x}-T_{0}\right) \cdot 2 \pi n}{T_{x}}\right] .
$$

In Figure 4 shows the graph of the absolute error of time variation at $10 \mathrm{MHz}$ for the coincidence pulse duration $-3 \mathrm{~ns}, 5 \mathrm{~ns}$.

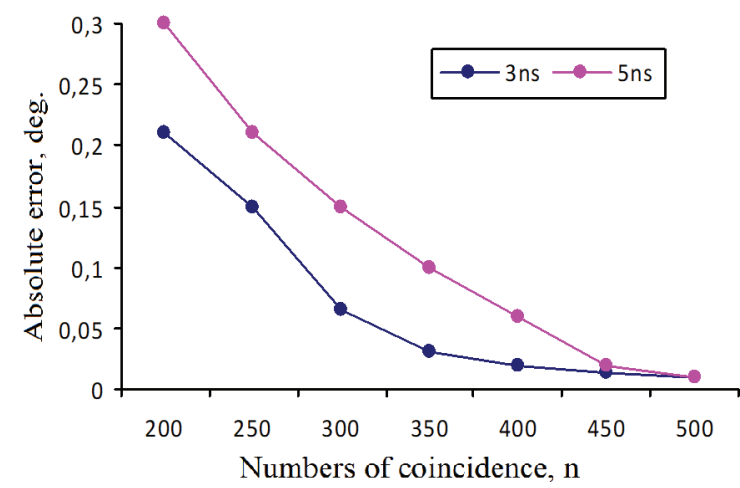

Figure 4 - Change of absolute error in time depending on pulse duration at frequency $10 \mathrm{MHz}$

As can be seen from Figure 4 that for different values of the duration of the coincidence pulses we have different values of absolute error at the beginning of the measurement, but with increasing number of coincidences, the results of the measurement approach to its true value. When using 200 matches, the absolute error reaches: pulse widths $3 \mathrm{~ns}-0.21^{\circ}$, $5 \mathrm{~ns}-0.3^{\circ}$. When using 300 matches: pulse duration 
$3 \mathrm{~ns}-0.065^{\circ}, 5 \mathrm{~ns}-0.15^{\circ}$. When using 400 matches: pulse duration $3 \mathrm{~ns}-0.02^{\circ}, 5 \mathrm{~ns}-0.06^{\circ}$. But, if using 500 coincidences for the duration of pulses of $3 \mathrm{~ns}$ and $5 \mathrm{~ns}$ of pulses, the absolute error was $0.01^{\circ}$.

Due to the instability of the input signals frequency, false coincidences may occur. In nonius methods this can lead to a gross error in the operation of the device. From expression (8) it can be seen that the counters can calculate how much one pulse is greater or less. In Figure 5 shows the dependence of absolute error on the presence of false coincidences using the double-matching method with the statistical accumulation of impulses:

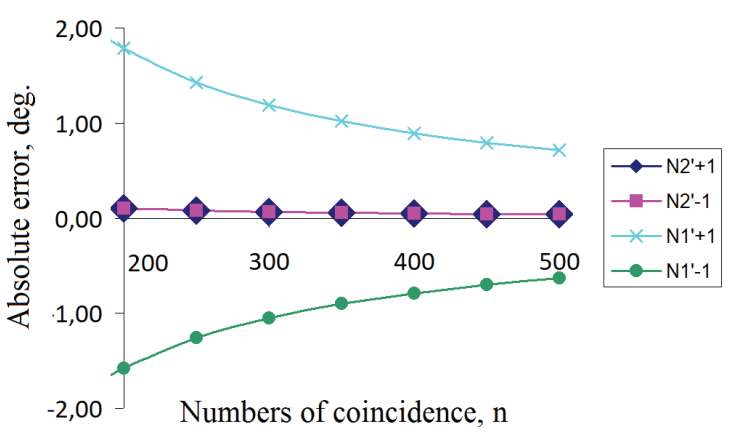

Figure 5 - Change of absolute error in time depending on the number of false coincidences at a frequency of frequency $10 \mathrm{MHz}$

The method of double matching allows us to eliminate the problem associated with a false coincidence of impulses (Figure 5), which may arise due to the instability of the input signal frequency. That is, due to the accumulation of measurement results with an increase in the number of coincidences, the absolute error of measurement is reduced.

\section{Conclusion}

As a result of the analysis of nonlinear methods for measuring phase shifts of signals, it has been established that the existing methods do not allow to solve the problem of precision increase in the phase meter devices at high frequencies effectively. For nonius methods, this is due to the need to reduce the duration of pulses with an increasing frequency of input signals and high requirements for the stability of the formation of periods of input and reference signals. In order to improve the accuracy and eliminate the defects of nonius meters, it is suggested that the authors use the method of double coincidence with the statistical accumulation of impulses.
The application of the double-coincidence method with the statistical accumulation of pulses solves the fundamental problem of nonius methods of measurement associated with the need to apply pulses of different durations with the simultaneous synchronization of the inclusion generators of nonius sequences. The method of double matching gives the opportunity to eliminate the fundamental limitation of nonius methods for the duration of coincidence pulses at high frequencies. The application of the statistical accumulation of coincidences pulses gives the possibility to generate pulse duration more than in nonius methods of measurements. This allows the use of continuous pulse generators regardless of the frequency of the input signals and measure phase shifts of signals over a wide frequency range using a single of Direct Digital Synthesizer to form reference signals. Due to the statistical accumulation of coincidence of pulses, the error of determining the angles of phase shift decreases due to the instability of the frequency of the reference and input signals. This method allows obtaining approximate phase shift values to complete the complete measurement cycle by using the statistical accumulation of pulse coincidences and reducing the equivalent pulse duration. On the basis of the method of double matching with the statistical accumulation of pulses, a structural diagram of an automated phase signal meter is developed. The 8-bit phase shift converter between the harmonic signals in the code is developed. The scheme is based on Altera's highspeed programmable logic EPM240T100C5N.

\section{References}

1. Henzler S. Time-to-Digital Converters. Springer, 2010, p. 124. DOI: $10.1007 / 978-90-481-8628-0$

2. Jimenez-Irastorza A., Sevillano J., Arizti F., Berenguer R., Rebollo I. Nonius based time-to-digital converter for low-power RFID sensory systems. RFID Technologies and Applications (RFID-TA), IEEE International Conference on, 15-16 Sept. 2011, pp. 2026. DOI: $10.1109 /$ RFID-TA.2011.6068610

3. Jimenez-Irastorza A., Beriain A., Sevillano J.F., Rebollo I., Berenguer R. A 0.6V and $0.53 \mu \mathrm{W}$ Nonius TDC for a Passive UHF RFID Pressure Sensor Tag, in RFID Technologies and Applications (RFID-TA), 2012 IEEE International Conference on, 5-7 Nov. 2012, pp. 216221. DOI: 10.1109/RFID-TA.2012.6404516

4. Lee Ke-Yu, Huang Chih-Feng, Huang SinSan, Huang Ke-Nung, Young Ming-Shing. A HighResolution Ultrasonic Distance Measurement System Using Nonius Caliper Phase Meter. IEEE Transactions on 
Instrumentation and Measurement, 2012, vol. 61, iss. 11, pp. 2924-2931. DOI: 10.1109/TIM.2012.2203871

5. Miao M., Zhou W., Wang B. Application of length Nonius in phase coincidence detection and precision frequency measurement. Rev. Sci. Instrum., 2012, vol. 83, pp. 024706. DOI: $10.1063 / 1.3678343$

6. Wenzler Axel, Steinlechner Siegbert. Nonlinear processing of $n$-dimensional phase signals. IEEE International Symposium on Circuits and Systems. Proceedings, 26-29 May 2002, pp. I-805-I-808.

DOI: $10.1109 /$ ISCAS.2002.1009963

7. Dong Shaofeng, Zhou Wei, Du Baoqiang, Changzhe Jiao. Ultra-high Resolution Phase Difference Measurement Method. IEEE International Frequency Control Symposium Proceedings, 21-24 May, 2012.

DOI: $10.1109 /$ FCS.2012.6243646

8. Jin Yuzhen, Xuan Zongqiang, Fuming Wang. A new method to eliminate dead zone of phase-comparison instruments adjacent to $0^{\circ}$ and $360^{\circ}$. International Conference on Advances in Mechanical Engineering and Industrial Informatics, 2015, pp. 527-531.

9. Polikarovskykh Oleksiy, Kovtun Lydmila, Karpova Lesya, Gula Igor. New Phase Accumulator for Direct Digital Frequency Synthesizer. 2018 International Scientific-Practical Conference Problems of Infocommunications. Science and Technology (PIC S\&T), 9-12 Oct. 2018, pp. 51-54.

DOI: 10.1109 /INFOCOMMST.2018.8632148

10. Polikarovskykh Oleksiy, Kovtun Lydmila, Karpova Lesya, Gula Igor. Method for correcting the time position of pulses in direct digital synthesizers of frequencies. 14th International Conference on Advanced Trends in Radioelectronics, Telecommunications and Computer Engineering, TCSET 2018 - Proceedings 2018-April, pp. 1209-1212.

DOI: $10.1109 /$ TCSET.2018.8336412 